\title{
Provisions and Accessibility of Natural Environment in Paediatric Wards
}

\author{
Roslinda Ghazali, Mohamed Yusoff Abbas \\ Faculty of Architecture, Planning \& Surveying, \\ Universiti Teknologi MARA, 40450 Shah Alam, Selangor, Malaysia \\ lindakeruing@gmail.com
}

\begin{abstract}
The provisions and accessibility of natural environment in Malaysian public paediatric wards in the Klang Valley were analysed further, based on data obtained in earlier studies pertaining to the general status and physical design trend of those wards. Data collected were based on personal observations, questionnaires, interviews and documentations, which involved eight paediatric wards located in both urban and non-urban areas. Findings revealed patients were less satisfied with the provisions and accessibility provided. While those negative feelings could impact upon their healing process, hence upon their Length of Stay (LOS), however, such correlation could not be determined in the present study.
\end{abstract}

Keywords: Paediatric community; natural environment; healing process; length of stay

eISSN 2398-4295 @ 2018. The Authors. Published for AMER ABRA cE-Bs by e-International Publishing House, Ltd., UK. This is an open-access article under the CC BY-NC-ND license (http://creativecommons.org/licenses/bync-nd/4.0/). Peer-review under responsibility of AMER (Association of Malaysian Environment-Behaviour Researchers), ABRA (Association of Behavioural Researchers on Asians) and cE-Bs (Centre for EnvironmentBehaviour Studies), Faculty of Architecture, Planning \& Surveying, Universiti Teknologi MARA, Malaysia.

DOI: http://dx.doi.org/10.21834/ajbes.v3i9.69 


\subsection{Introduction}

The natural environment as a very important contributor towards healing, had been known for years, and well documented in the literature (eg. Ulrich et al., 2004, Mayer et.al., 2009). Nevertheless, Ananth (2008), in her suggested Optimal Healing Environment (OHE), had considered the natural environment as just an aspect of one component (the Building Healing Spaces) of the overall seven components. She opined that OHE is determined by both external and internal environment, where the social, psychological, physical, spiritual, and behavioral components of healthcare support stimulate the body's innate capacity to heal itself. Pivoted on the Practicing Healthy Lifestyle component, the other components of the Inner Environment - Developing Healing Intention, Experiencing Personal Wholeness, Cultivating Healing Relationship, and that of the Outer Environment - Applying Collaborative Medicine, Creating Healing Organisation, and Building Healing Spaces, as shown in Figure 1. All the components combined and act in unison would be responsible in the creation of the $\mathrm{OHE}$, which only then would aid the recovery process, and hence, capable of reducing the Length of Stay (LOS).

This paper investigated upon the current status and implications in the provisions of the natural environment, in paediatric wards of Malaysian public hospitals in the Klang Valley. The objective attempted to determine whether the provisions of only the natural environment, as well documented in the literature mentioned earlier, could provide impact towards the creation of a healing environment. The implication would be on the speedier recovery of patients, thus reducing their LOS which ultimately resulted in the cost-saving benefits for the government's healthcare budget.

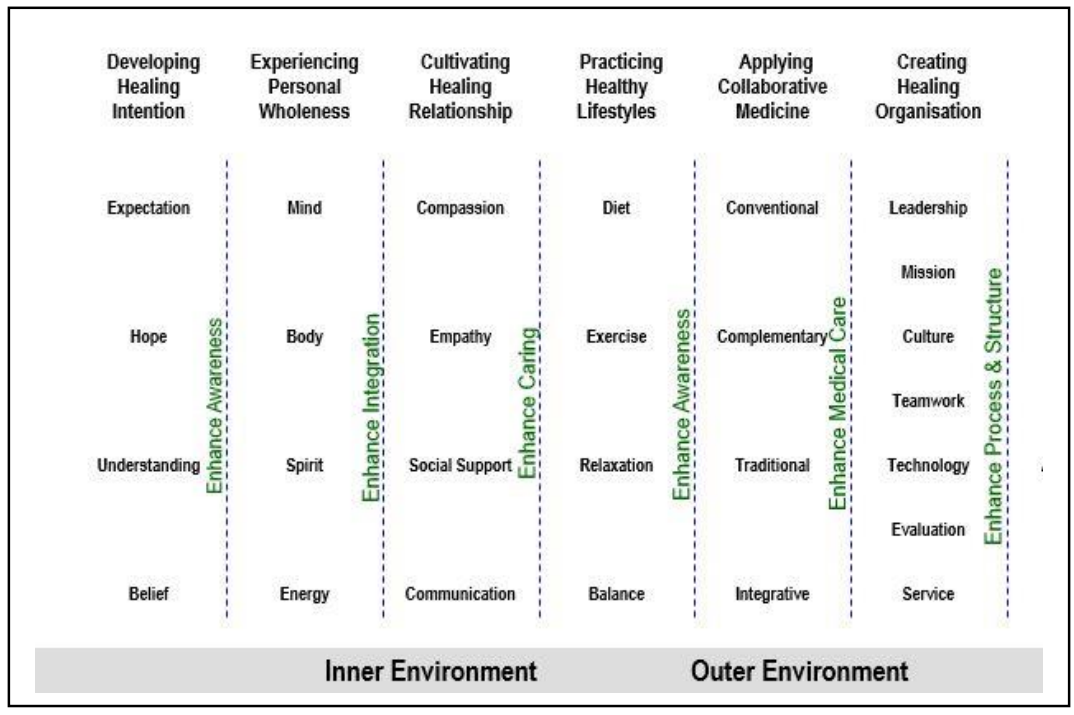

Fig. 1. The Optimal Healing Environment (Source: Ananth, 2008) 
The present retrospective study was based on data collected from an earlier study which had reported on just the general status and the physical design trend of those wards. Those general findings were revealed in previous conferences and published in the proceedings. The methodology involved retrieving In-patient data, personal observations, interviews and questionnaires based on two UK.s NHS evaluation toolkits (validated by evaluation upon more than 600 hospitals worldwide) - the AEDET Evolution which measured the quality of the physical environment, and the ASPECT, which measured users satisfactory levels on the facilities provided. For the purpose of the present study, only the selected relevant data from the earlier general study reported were probed further in the analysis. Those involved data that specifically involved only aspects on the provisions of the natural environment.

\subsection{Literature Review}

Studies on the positive impacts of natural environments and the resultant speedier recovery process amongst patients are well documented in the literatures. This section relates the present study to previous studies conducted by other authors on the similar topic related to provisions of the natural environment. The issues for the present study were derived from the literatures reviewed. Those involved functions of the windows; positive distractions; setting preferences; and impacts of natural environment, natural lighting, and natural sound towards the healing process.

Studies done by Kaplan (2001) noted that the functions of windows are to permit access to the sky which allowed the sight to the weather. In addition, Kaplan revealed that individuals who spend time outdoors, take walks or hikes, go to a park, or bike or jog in the neighborhood were more likely to indicate that they felt positive, focused, effective, and alert. Similarly, Suresh, et al. (2005) reported that views of nature through windows benefited patients recovering from surgery and affected the physical health aspect of individuals. Velarde, et al. (2007), found the evidence of health and well-being effects related to exposure to visual landscape. They also found that the natural landscape gave stronger positive health effect compared to urban landscape. Their research concluded that hospitalized patients exposed to landscape related to reduced stress and recovery from illness, behavioral changes and general well-being. Patients are suggested to view natural landscape during a walk, viewing from the window, looking at a picture or a video, or experiencing vegetation around the building. Studies done by Ulrich (2002) found that green leaf, flowers, water, harmonious nature sounds such as birds, breezes and water visible wildlife and other nature enhanced patient and family satisfaction with the healthcare provider and the overall quality of care. Ulrich noted that patients who have views towards garden and plants, strongly had connections with those natural features, which influenced their moods. Ulrich benefited the patients in terms of cost in delivering healthcare because of their shorter LOS and improved staff satisfaction as well.

Positive distraction has been found to effectively reduce stress and anxiety. Positive distraction means environment that could create calmness, is soothing, relaxing and comfort to hospitalized patients. Sources of such positive distractions could be from both 
the internal or external environment. Sources from the internal environment include art and colour, lighting, space, outdoor view to nature, safety and ergonomic and alternative therapies. While sources from the external environment include sound, artwork in the garden and playground, nature and garden (Abbas and Ghazali, 2011). Barnhart et al. (1998) explored the setting preference that would affect behavior. Their study revealed a strong preference between patient and staff for natural settings, particularly when linked to certain preferred behaviours. They also found that the users preferred settings within the natural and open constructs for passive-type activities; however, natural and enclosed settings were preferred for active-type activities suggesting that behaviour preferences are linked to setting preference. These findings indicated a significant relationship upon the users preferred behaviour and setting constructs. Mayer et al, (2009) in their experiment found that hospitalized patients who were exposed to nature increased connectedness to nature, had positive emotions, and the effects are more dramatic for actual nature rather than for virtual nature. They concluded that nature contributed to the healing process. Hence, designers are advised to consider the garden as part of their design features. They should also consider other features such as, water element, path to walk, plants, flowers, etc. Perhaps that could give benefit in progressive behaviours towards calm, to reduce stress, relaxed and forgetting worries.

According to Joseph (2006), the presences of windows and access to natural daylight have been linked with increased satisfaction upon the users. The impacts of natural lighting on human health and performance by enabling performance of visual tasks, controlling the body's circadian system, and by enabling critical chemical reactions in the body affecting mood and perception, by reducing depression among patients in the hospitals. The light impacts outcomes in healthcare settings would decrease length of stay in hospitals, improved sleep and circadian rhythm, lessened agitation among dementia patients, eased pain, and improved adjustment to night-shift work among staff. Furthermore, exposure to light is critical for vitamin D metabolism in the human body and light exposure used as a treatment for neonatal 'hyperbilirubinaemia'. Joseph concluded that patients exposed to light are important for health and well-being of patients as well as staff in healthcare settings. A combination of daylight and electric light should be incorporated into lighting design in healthcare settings, not only because it is beneficial to patients and staff, but also because it is light delivered at no cost and in a form that most people preferred.

Studies done by Joader, et al. (2009) found that the use of natural lighting is to enlighten interiors and for its natural healing powers. An evidence-based study by them found that natural lighting gave impacts on patients' health and gradual recovery from light on patient's eye or skin. They explored the impacts of light on the psychological diseases due to light incident on the retina of the eye causing adaptation of individual endocrine and hormone. In terms of the healing process, Phiri (2003) opined that natural lighting benefits on the psychological effects to individuals such as the workers and patients. He found that natural lighting increased worker productivity and expedited patients' recovery. He also suggested that designer consider the optimal widths of corridors in order to provide a transitional space such as appropriate day lighting, views, storage and art.

In relation to sound of nature, Vapaa (2002) concurred that "heavy water rushing out of 
a fountain can offer enough white noise to drown out other distracting sounds such as traffic" (p.67). The sound of slow dripping fountains provided calmness and rhythm in the garden as a meditative garden. In addition, Vapaa noted that the grass and bamboos, are not only for their sound but also for their beauty when blown by the wind. Furthermore, a variety of insects and birds are attracted to plants in the garden, which enhanced further the natural environment.

\subsection{Methodology}

As mentioned earlier, the methodology of the present study was described in detail in previous conference proceedings published. As such, only a summary of the research design shall be described in this section.

The Post Occupancy Evaluation (POE) upon the Malaysian public paediatric wards was chosen as the strategy for the present study because such a study has never been conducted, as concurred by senior medical staffs interviewed. In addition, the strategy truly depicted the current status of the wards. The study involved eight paediatric wards located in both urban and nonurban areas, in the Klang Valley. The hospitals involved were strategically identified in terms of the year those were built which depicted the design trend of the last three decades - the 1980s, 1990s and 2000s.

Table 1. List of Hospitals: The year built, hospital location and number of respondent

\begin{tabular}{lllllll}
\hline & Hosp. & $\begin{array}{l}\text { Year } \\
\text { Built }\end{array}$ & Area & $\begin{array}{l}\text { No. of Respondent } \\
\text { Beds }\end{array}$ & $\begin{array}{l}\text { Respondent } \\
\text { (Staff) }\end{array}$ & (Patients) \\
\hline 1 & KG & 1985 & Urban & 36 & 27 & 23 \\
2 & IP & 1991 & Urban & 32 & 30 & 28 \\
3 & KJ & 1999 & Urban & 40 & 26 & 27 \\
4 & PA & 1999 & Urban & 28 & 24 & 30 \\
5 & SG & 1999 & Non-Urban & 28 & 28 & 29 \\
6 & SD & 2005 & Non-Urban & 28 & 26 & 29 \\
7 & AG & 2006 & Non-Urban & 28 & 27 & 29 \\
8 & SB & 2007 & Non-Urban & 28 & 27 & 22 \\
\hline Total Respondent & & & 215 & 217
\end{tabular}

The manner data was collected involved the 2009 in-patients data retrieved, evaluation toolkits namely AEDET Evolution (DS Estates and Facilities, 2008a) and ASPECT Evaluation toolkit (DS Estates and Facilities, 2008b), personal on-site observation, floor plan of paediatric wards and photographic documentation. The AEDET (Achieving Excellence Design Evaluation Toolkit) Evolution was used to evaluate the physical environment through a series of statements, which consists of three areas namely Impact, Build Quality and Functionality. The AEDET forms were filled up by the researchers based on their personal 
on-site observation of the physical environment of the wards. The weightage for the best score is 6 , to express a level of virtually complete agreement, while the poorest score is 1 used to express a level of virtually no agreement. Profiles of the eight hospital wards involved as the setting for the study are as shown in Table 1.

\subsection{AEDET Evolution}

The AEDET Evolution was used to evaluate the physical environment. The toolkits evaluated both the strengths and weaknesses of the physical design of hospitals. The researchers filled up the AEDET forms during their personal observation and site visit. The form consisted of three areas namely Impact, Build Quality and Functionality. This paper focused only on the Impact Staff and Patient Environment which involved factors on views, accessibility and comfort of the users.

\subsection{ASPECT Evaluation}

The ASPECT (A Staff and Patient Environment Calibration Toolkit) was modified into survey questionnaires to evaluate users' satisfaction level. The survey questionnaires distributed to respondents involved users of the paediatric wards, which included patients / carers, nurses and other staffs. Overall, the survey involved respondents from 217 patients and 215 nurses as tabulated in Table 1. Floor plans were used to locate the patient's beds in relation to the position of the windows. Those synchronised with the particular respondent's questionnaire, especially pertaining to issues such as viewing outside of the ward, accessibility to outside and comfort upon patients.

\subsection{Limitations and delimitations}

Amongst the limitations included time constrains, incomplete questionnaire responses, and limited samples. The time constrains involved delayed approval from the Ministry of Health $(\mathrm{MOH})$ and the National Medical Research Institute (NMRI), together with the slow release of the confidential in-patient data which had to be screened by the hospitals' administrative staffs concerned. Several questionnaires responses were incomplete as the carer were more concernecd with the wellbeing of the patients rather than participating in the survey. The limited samples were based only in selected public hospitals in the Klang Valley, whch might not be the true representation of the nation.

Delimitations involved patients' age group and ward sizes. Samples were delimited to patients of ages between $3-6$ years old. Only $28-40$ bedded wards were involved with the study, for ease of comparison with the newer wards designed.

\subsection{Findings and Analysis}

This section described the findings based on the data obtained. Only relevant findings to the topic of the present paper were highlighted. Those involved findings of In-Patient Data, specifically on Length of Stay (LOS); Satisfactory levels of users of the wards in relation to provisions of the natural environment; Personal observation on accessibility to the natural 
environment ; and Relationship between patient's bed and window locations.

\subsection{In-Patient Data (2009)- Length of stay}

Overall, while majority ( $65 \%$ and above) of the patients' length of stay were within the 1-5 days compulsory medical observation category, some variations amongst the hospitals were also observed for a longer duration; $6-10$ days $(6 \%-20 \%), 11-15$ days (below $7 \%$ ), and 16-20 days and above (less than $2 \%$ ) as shown in Figure 2. While IP (U)-91 being a specialized hospital can be discounted, amongst the higher proportion with longer stay observed were at SD (NU) -05 (> 20days); SG (NU)-99 (6-10 days), as shown in Fig. 2.

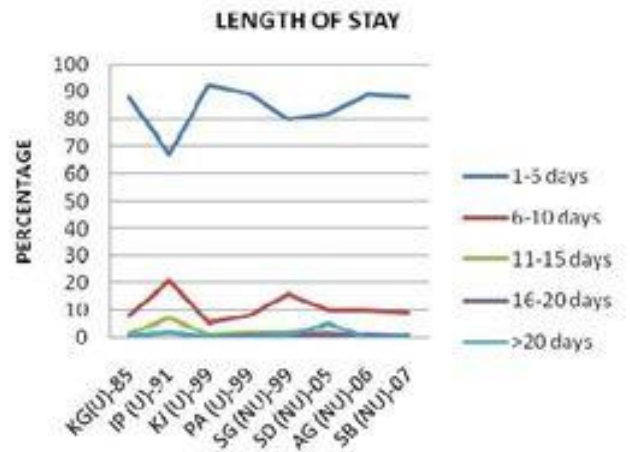

Fig. 2. In-Patient Data 2009: Length of stay distribution at the eight hospitals.

\subsection{AEDET Evolution and ASPECT Evaluation}

Of relevance to the study in both the AEDET Evolution and ASPECT evaluations were in terms of good views inside and out of the building, and accessibility to outdoors. In terms of the physical environment, overall the AEDET Evolution evaluated a more positive trend in terms of views inside and out of the building, as compared to the accessibility to the outside with amongst the least satisfactory which included SG(NU)-99, one of the ward with slightly longer LOS. In relation to satisfactory levels amongst the users, overall, the ASPECT evaluated just average in almost all the wards, which included both the wards with slightly higher proportion of longer LOS.

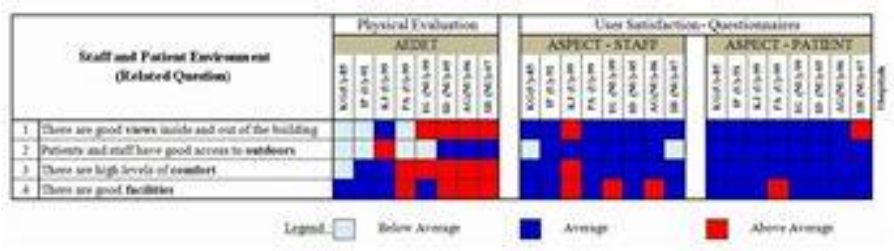

Fig. 3. The AEDET and ASPECT findings 


\subsection{Personal on-site observation}

The researchers observed the relationship of patients' activities in particular while they were in bed, or at the playroom and garden. Natural lighting showered majority of the wards. Four of the hospitals:- $K G(U)-85$, PA (U)-99, SG (NU)-05 and SB(NU)-07 were without outdoor garden, while the remaining hospitals with outdoor garden only allowed children to access the garden at certain time only. The data analysed on the influence of the physical environment upon the patients' behavior were as recorded a s in Table 2.

Table 2. Personal on-site observation

\begin{tabular}{|c|c|c|c|c|}
\hline \multicolumn{2}{|c|}{ Hospitals } & \multirow{2}{*}{$\begin{array}{l}\text { Ward } \\
\text { (Natural } \\
\text { Lighting) }\end{array}$} & \multirow{2}{*}{$\begin{array}{l}\begin{array}{l}\text { Playroom } \\
\text { (Accessibility) }\end{array} \\
\begin{array}{l}\text { Accessible at } \\
\text { certain time }\end{array}\end{array}$} & \multirow{2}{*}{$\begin{array}{l}\text { Outdoor } \\
\text { Garden } \\
\text { (Accessibility) } \\
\text { Not provided }\end{array}$} \\
\hline 1 & $K G(U)-85$ & & & \\
\hline 2 & IP(U)-91 & Yes & $\begin{array}{l}\text { Accessible at } \\
\text { certain time }\end{array}$ & \multirow{2}{*}{$\begin{array}{l}\text { Accessible at } \\
\text { certain time } \\
\text { Accessible at } \\
\text { certain time }\end{array}$} \\
\hline 3 & $K J(U)-99$ & Yes & $\begin{array}{l}\text { Accessible at } \\
\text { certain time }\end{array}$ & \\
\hline 4 & PA(U)-99 & Yes & $\begin{array}{l}\text { Accessible at } \\
\text { certain time }\end{array}$ & Not provided \\
\hline 5 & SG(NU)-99 & Yes & $\begin{array}{l}\text { Accessible at } \\
\text { certain time }\end{array}$ & Not provided \\
\hline 6 & $S D(N U)-05$ & Yes & $\begin{array}{l}\text { Accessible at } \\
\text { certain time }\end{array}$ & \multirow{2}{*}{$\begin{array}{l}\text { Accessible at } \\
\text { certain time } \\
\text { Accessible at } \\
\text { certain time }\end{array}$} \\
\hline 7 & $A G(N U)-06$ & Yes & Not provided & \\
\hline 8 & $\mathrm{SB}(\mathrm{NU})-07$ & Yes & $\begin{array}{l}\text { Accessible at } \\
\text { certain time }\end{array}$ & Not provided \\
\hline
\end{tabular}

\subsection{Relationship between beds and window positions}

The results revealed that overall, the satisfactory levels amongst the patients differed in relation to the positioning of their beds in relation to the windows. The main reason seemed obvious because of the better view to the outside for beds nearer to the windows. In particular, where the outside views were in relation to the natural environment.

Findings also revealed the dissatisfaction amongst patients, where provisions of the gardens were inaccessible, or with controlled accessibility. The implication is significant since dissatisfaction amongst patients have a negative impact in the recovery process. Further implications are upon designers who should not only provide the natural environment, but equally more important is the accessibility to such provisions. 


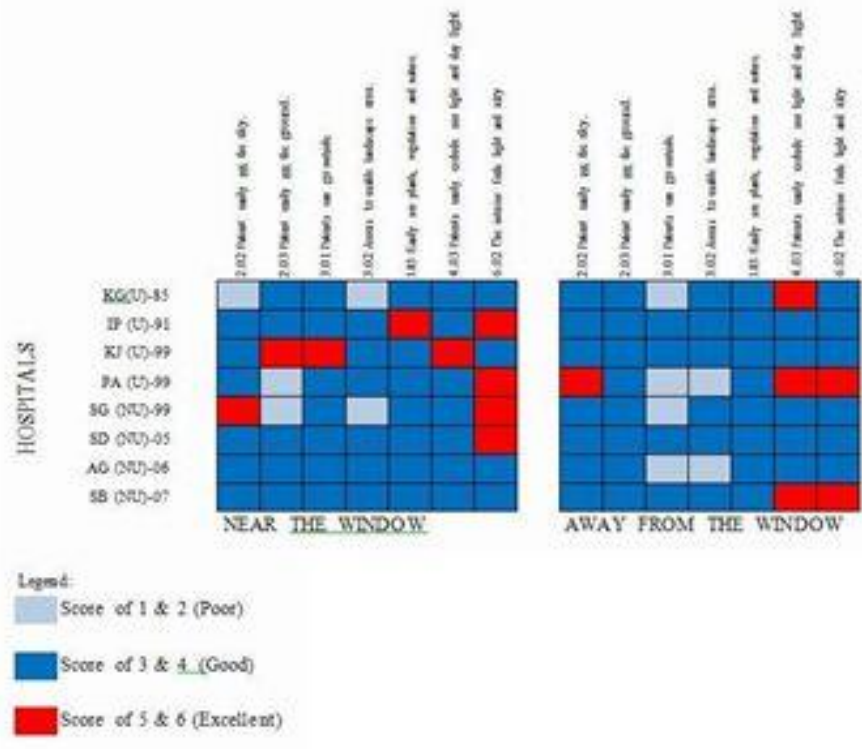

Fig. 4. ASPECT Evaluation: Relationship between patient's bed and window

\subsection{Discussions}

The objective of the present study was to determine whether the provisions of only the natural environment would provide impact towards the creation of a healing environment. This section discussed the relevant findings highlighted in the previous section, in relation to the issues raised which provided the context in which the present study was conceived. Those involved different duration of LOS; Users satisfactory levels on the provisions of the natural environment; Issues on accessibility to those provisions; and patient's bed positioning in relation to the window. Implications beyond the confines of the present study were also considered.

In relation to duration for LOS, there were higher proportions amongst some of the wards with longer durations, most notably the SD (NU) -05 (> 20days); SG (NU)-99 (6-10 days), both located in non-urban areas, with the worst situation which involved the newer built in 2005. Meaning, despite the standard provisions provided amongst the public hospitals, there exist peculiar environment in each of the ward that could have made the environment less conducive towards healing, hence the prolonged LOS.

However, both wards scored above average in the AEDET Evolution evaluation on the physical environment which concerned good views inside and out of the building. In relation to having good access to outdoors, SG (NU)-99 scored below average, while the SD (NU)05 managed just an average score. Meanwhile both wards scored just average on both aspects, based on the ASPECT evaluation which evaluated users satisfactory levels. Personal observation revealed all wards were with natural lighting. However, there was no accessibility to outside garden for SG (NU)-99, together with $50 \%$ of the other wards; 
while controlled accessibility for SD (NU)-05 with $50 \%$ of the other wards. In relation to position of beds to window locations, for the near the window situation, SG(NU)-99 scored below average on two aspects, patients could not see easily the ground, similarly scored by $\mathrm{PA}(\mathrm{U})-99$, and patients were not accessible to usable landscape area, similarly scored by $K G(U)-85$. For beds away from the window situation, the SG(NU)-099 were given below average score in relation in terms of accessibility to outside, but that situation also was experienced in $50 \%$ other wards. Meanwhile the $\mathrm{SD}(\mathrm{NU})-05$ scored just average for both situations.

Based on the analysis above, it is difficult to establish a correlation between LOS with the provisions and accessibility to the natural environment, despite users were just averagely satisfied with such situation. Perhaps, there is no correlation at all as suggested by Ananth (1981), whereby an optimum healing environment is determined by both external and internal environment, where the social, psychological, physical, spiritual, and behavioral components of healthcare support stimulate the body's innate capacity to heal itself.

The implication here is, it is less fruitful to consider just an aspect of a component that could lead towards the creation of a healing environment. Various other positive components combined, and act in unison would be responsible for the creation of a healing environment, which only then would aid the recovery process and hence capable of reducing the LOS, which eventually could lead to cost-saving benefits in the budget for healthcare.

\subsection{Conclusion}

Based on further analysis upon data obtained from earlier studies on the general status and design trends of eight Malaysian public paediatric wards in the Klang Valley, the findings revealed patients were less satisfied with the provisions and accessibility of natural environments in the wards. Such negative feelings could impact upon their healing process, hence upon their LOS. However, such co-relation could not be established in the present study. This could be due to focusing on just one component, instead of the overall seven for an OHE, as suggested by Ananth (1981).

Additionally, due to differences in environmental and cultural context, future studies should develop a Malaysian Model Evaluation Toolkit (MMET), which can be based from the UK model used for the present study.

\section{Acknowledgement}

Our heartiest gratitude to the Malaysian Ministry of Higher Education for the research grant awarded for this study.

\section{Special Note}

This paper was developed further from the paper published by the same authors in Healing environment of paediatric wards, Proceedia - Social and Behavioral Sciences, 5, 2010, 948-957, Elsevier, available online 21 September 2010. Earlier findings were revealed in the Proceedings of AicE-Bs 2010, Grand Margherita Hotel, Kuching, Malaysia, 7-9 
December 2010, the Proceedings of AcE-Bs 2010, Riverside Majestic Hotel, Kuching, Malaysia, 7-8 July 2010, while the pilot study was revealed in the Proceedings of 1nCEBS 2009, Shah Alam, Malaysia, 14-15 November 2009.

\section{References}

Abbas, M.Y., and Ghazali, R. (2011). Physical Environment: The Major Determinant Towards the Creation of a Healing Environment? Procedia - Social and Behavioral Sciences, 30, 1051-1058. Elsevier (Available online: 29 December 2011).

Ananth, S. (2008). Healing Environments: the next natural step. Explore, 4 (4) , 274.

Barnhart, S.K., Perkins, N.H., Fitzsimonds, J. (1998). Behaviour and Outdoor Setting Preferences at a Psychiatric Hospital. Landscape and Urban Planning, 42, 147-156.

Creel, L.(2002). Children's Environmental Health: Risks and remedies. Making the Link: Population Reference Bureau, 1-7.

DH Estates \& Facilities (2008), A Staff and Patient Environment Calibration Toolkit (ASPECT) : Summary, NHS, UK. Retrieved January 15, 2008 from http://www.dh.gov.uk/en/Publicationsandstatistics/Publications, PublicationsPolicyAndGuidance/DH_082087.

DH Estates \& Facilities (2008), Achieving Excellence Design Evaluation Toolkit (AEDET), Summary, NHS, UK. Retrieved January 15, 2008 from http:/www.dh.gov.uk/en/Publicationsandstatistics/Publications/, PublicationsPolicyAndGuidance/DH_082089.

Joarder, M. A. R., Price, A.D.F. and Mourshed, M., (2009). Systematic study of the therapeutic impact of daylight associated with clinical recovery. The Proceedings of PhD Workshop of HaCIRIC's International Conference Improving Healthcare Infrastructures through Innovation 1 st April 2009, 25-31.

Joseph, A. (2006). The Impact of Light on Outcomes in Healthcare Settings. The Center for Health Design, 2.

Kaplan, R. (2001). The Nature of the View from Home: Psychological Benefits. Environment and Behavior, 33, 507.

Mayer,F. S., Frantz, C. M., Senecal, E.B. and Dolliver, K., (2009). Why Is Nature Beneficial? The Role of Connectedness to Nature. Environment and Behavior, 41(5), 607-643.

Morrongiello, B.A. and Rennie, H., (1998). Why Do Boys Engage in More Risk Taking Than Girls? The Role of Attributions, Beliefs, and Risk Appraisals. Journal of Pediatric Psychology, 23(1), 33-43.

Phiri,M., (2003). One Patient One Room Theory and Practice: An evaluation of The Leeds Nuffield Hospital University of Sheffield. NHS Research Project, School of Architecture, Arts Tower, Sheffield, pp 120.

Said, I., Salleh, S.Z., Abu Bakar, M.S. (2002). Garden as Environmental Intervention in Restoration Process of Hospitalized Children. Department of Landscape Architecture, Faculty of Built Environment, Universiti Teknologi Malaysia, Skudai, Johor.

Suresh, M., Franz, J. and Smith, D., (2005). Holistic Health and Interior Environment: Using the Psychoneuroimmunogical Model to Map Person-Environment Research in Design. The Proceedings of Smart Systems -Postgraduate Research Conference 2005,188-195.

Ulrich, R. S., (2002). Health Benefits of Gardens in Hospitals. Paper for conference: Plants for People International 
Exhibition Floriade 2002.

Vapaa,A.G., (2002). Healing Gardens: Creating Places for Restoration, Meditation, and Sanctuary. What are the defining characteristics that make a healing garden? By MA Virginia Polytechnic Institute and State University, College of Architecture and Urban Studies.

Velarde, M.D., G. Fry and Tveit, M., (2007), Health Effects of Viewing Landscapes Landscape Types in Environmental Psychology. Science Direct, Urban Forestry \& Urban Greening, 6, 199-212. 